\title{
Optimization of the secondary electron yield of laser-structured copper surfaces at room and cryogenic temperature
}

\author{
Sergio Calatroni ${ }^{*}$, Elisa Garcia-Tabares Valdivieso, Ana Teresa Perez Fontenla, \\ Mauro Taborelli, Holger Neupert, Marcel Himmerlich, and Paolo Chiggiato \\ CERN, European Organization for Nuclear Research, Esplanade des Particules 1, \\ 1217 Meyrin, Switzerland \\ David Bajek, Stefan Wackerow, and Amin Abdolvand \\ School of Science and Engineering, University of Dundee, Dundee DD1 4HN, Scotland, United Kingdom
}

(Received 1 November 2019; accepted 19 February 2020; published 11 March 2020)

\begin{abstract}
Electron cloud ( $e$-cloud) mitigation is an essential requirement for proton circular accelerators in order to guarantee beam stability at a high intensity and limit the heat load on cryogenic sections. Laser-engineered surface structuring is considered a credible process to reduce the secondary electron yield (SEY) of the surfaces facing the beam, thus suppressing the $e$-cloud phenomenon within the high luminosity upgrade of the LHC collider at CERN (HL-LHC). In this study, the SEY of Cu samples with different oxidation states, obtained either through laser treatment in air or in different gas atmospheres or via thermal annealing, has been measured at room and cryogenic temperatures and correlated with the surface composition measured by $\mathrm{x}$-ray photoelectron spectroscopy. It was observed that samples treated in nitrogen display the lowest and more stable SEY values, correlated with the lower surface oxidation. In addition, the surface oxide layer of air-treated samples charges upon electron exposure at a low temperature, leading to fluctuations in the SEY.
\end{abstract}

DOI: 10.1103/PhysRevAccelBeams.23.033101

\section{INTRODUCTION}

Electron cloud (e-cloud) mitigation is an essential requirement in proton circular accelerators for beam stability and reduction of the heat load in cryogenic sections at a high intensity [1,2]. In the Large Hadron Collider (LHC) at CERN [3], this requirement is achieved using activated nonevaporable getter coatings [4] in the room-temperature sections and via beam scrubbing of the copper beam screen surfaces in the cryogenic sections. Both solutions provide a low enough secondary electron yield (SEY) of the beamfacing surfaces below the $e$-cloud multiplication threshold, thus effectively suppressing the $e$-cloud. For the high luminosity upgrade of the LHC (HL-LHC), new ad hoc surface treatments are envisaged on selected cryogenic components, in particular, on the beam screens of the inner triplet magnets focusing the beam in the four HL-LHC interaction regions. Because of the modified HL-LHC beam parameters, a reduction of the SEY below what may be achieved with beam scrubbing is needed in order to maintain the heat load on the cryogenic system within

\footnotetext{
*sergio.calatroni@cern.ch
}

Published by the American Physical Society under the terms of the Creative Commons Attribution 4.0 International license. Further distribution of this work must maintain attribution to the author(s) and the published article's title, journal citation, and DOI. acceptable margins, due to the power deposited onto the cold surfaces by the $e$-cloud if this would occur $[5,6]$.

Amorphous carbon (a-C) coating [7] is the baseline surface treatment selected in the HL-LHC project for $e$-cloud mitigation and will be applied through a combination of ex situ and in situ coatings, for both integration of new cold magnets and retrofitting of existing ones [8]. Laser surface structuring (LESS) $[9,10]$ of the copper surfaces facing the beam is also being considered as a possible process to reduce the SEY, due to the feasibility of in situ treatment [11].

In order to optimize laser processing conditions, we have treated several samples in air and in a protective atmosphere of nitrogen or argon and measured their SEY at both room and cryogenic temperatures. These results are correlated with x-ray photoelectron spectroscopy (XPS) analyses of the surface composition combined with thermal annealing, in order to characterize the differences in the degree of surface oxidation.

\section{EXPERIMENTAL SETUPS}

\section{A. Sample preparation and laser treatment}

Samples were prepared out of 1-mm-thick copper UNS C10100 ("OFE copper") laminated sheets, cut into disks of $29 \mathrm{~mm}$ diameter, degreased, and passivated at CERN following standard procedures for UHV [12] prior to shipping to the University of Dundee for laser treatment. 


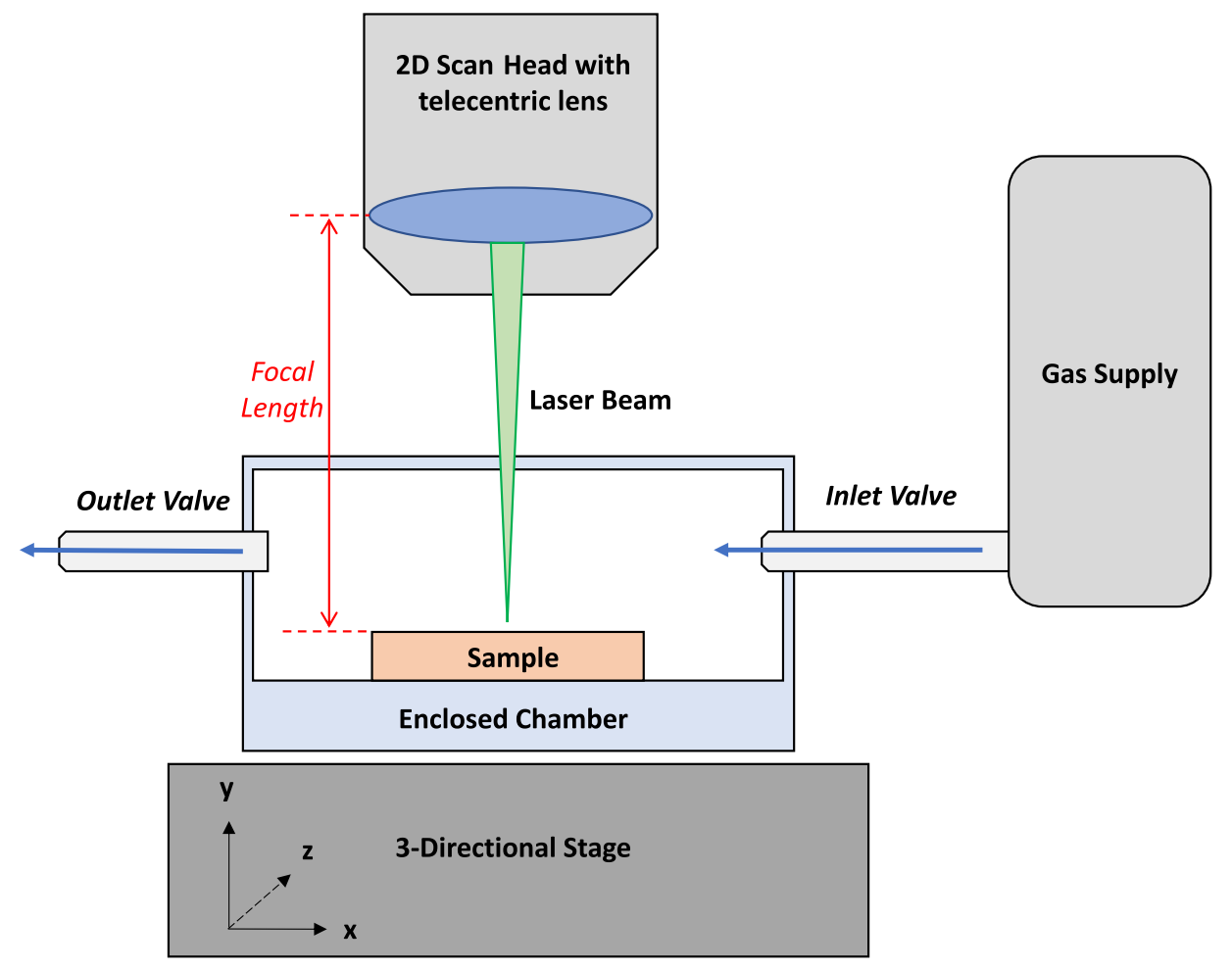

FIG. 1. Schematics of the laser treatment setup. The chamber was filled with gas of $99.998 \%$ purity at a flow rate of approximately $5 \mathrm{~L} / \mathrm{min}$. The system was then allowed to reach equilibrium for several minutes before processing commenced.

The laser surface structuring was performed in a similar way as discussed in Ref. [13] using a linearly polarized pulsed (10 ps) laser beam with a wavelength of $532 \mathrm{~nm}$ at a repetition rate of $200 \mathrm{kHz}$. The laser beam had a Gaussian intensity profile $\left(M^{2}<1.3\right)$ and was focused onto the surface using a telecentric lens that allowed for offsetting the off-axis deflection of the beam through the focusing lens system. The diameter of the focused spot-between the points where the intensity has fallen to $1 / e^{2}$ of the central value-was measured to be about $12 \mu \mathrm{m}$. Throughout the experiments, an average laser pulse energy of $5 \mu \mathrm{J}$ was used.

The laser beam was raster scanned across the target surface at a scan velocity of $10 \mathrm{~mm} \mathrm{~s}^{-1}$ using a computercontrolled scanner system. Two different scanning techniques were employed for these experiments, namely, line-hatched (LH) scanning and cross-hatched $(\mathrm{CH})$ scanning. For the LH pattern, the laser was scanned only in one direction, leading to approximately 240 pulses per spot being fired onto the sample surface, while for the $\mathrm{CH}$ pattern the laser was scanned over the surface in two perpendicular directions to form a grid pattern, effectively doubling the number of laser pulses per spot. Spacing between scan lines (the hatch distance) was approximately $24 \mu \mathrm{m}$ in both cases. In the present experiments, the samples were treated at atmospheric pressure either in air or by irradiating the samples through a glass enclosure, which was backfilled with argon or nitrogen (see Fig. 1). For the LH pattern, samples were produced using all three different atmospheres, while $\mathrm{CH}$ patterned samples were generated only in air. It was demonstrated in Ref. [13] that the $\mathrm{LH}$ and $\mathrm{CH}$ patterns produced in air result in a very similar SEY, with half the processing time for the LH pattern, which made it the treatment of choice in the later phases of the study.

After treatment, the samples were wrapped in silk paper and a layer of aluminum foil and then packed into sealed polyethylene bags filled with nitrogen prior to shipping. The time between the sample laser treatment and the first room-temperature SEY and XPS measurement was a couple of weeks.

\section{B. Sample characterization}

XPS was used to identify and quantify elemental composition of the surfaces as well as to distinguish the oxidation states. XPS spectra were collected by a commercial system equipped with a hemispherical energy analyzer and a monochromated $\mathrm{Al} \mathrm{x}$-ray source. The binding energy scale is calibrated by measuring reference spectra of sputter-cleaned polycrystalline $\mathrm{Au}, \mathrm{Cu}$, and $\mathrm{Ag}$ samples. The average pressure in the XPS analysis chamber is about $5 \times 10^{-10} \mathrm{mbar}$, and the samples were introduced via a load-lock system. The sample holder allows baking the samples in situ up to $300^{\circ} \mathrm{C}$.

Room-temperature SEY measurements were performed inside this same system by means of an electron gun and a revolving sample holder. The SEY is measured in two 
consecutive steps: In the first step, the sample is positively biased (nominal $+45 \mathrm{~V}$ ) while the electron beam energy is scanned between 10 and $1200 \mathrm{eV}$. All secondary electrons are thus collected back on the sample. We define the sample current $I_{\mathrm{pe}}$ measured in this situation to be the current of the primary electrons. In the second step, the sample is negatively biased (nominal $-45 \mathrm{~V}$ ), and escaping secondary electrons generated by the primary electron beam are driven away from the sample. We define the sample current $I_{\text {abs }}$ measured in this case as the absorbed current. The SEY $\delta$ is then determined by $\delta=\left(I_{\mathrm{pe}}-I_{\mathrm{abs}}\right) / I_{\mathrm{pe}}$. The presented data are averaged values from three different spots of about $2 \mathrm{~mm}^{2}$ across the sample surface, and the precision of the measured SEY values is estimated to be \pm 0.05 . The total electron dose for each measured curve is about $10^{-6} \mathrm{C} \mathrm{mm}^{-2}$.

SEY measurements at cryogenic temperatures were carried out in a separate custom-made system ("coldSEY") described in detail in Ref. [14]. This system is an all-metal UHV system with an operating base pressure of $1 \times 10^{-9}$ mbar. A venting of the system is required for sample exchange; thus, before all measurements, the entire vacuum system is baked, typically for $20 \mathrm{~h}$ at $150^{\circ} \mathrm{C}$ while the sample is kept at $120^{\circ} \mathrm{C}$. A cold head cooled with liquid helium acts as the sample holder and is used to cool the

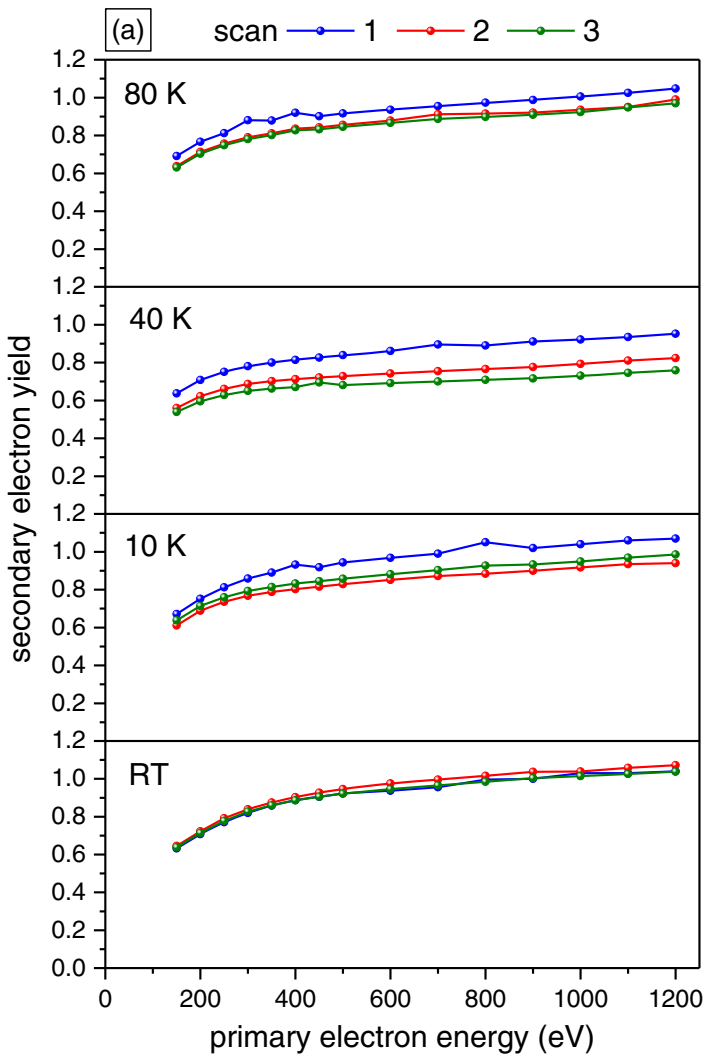

sample surface to a temperature of $\approx 10 \mathrm{~K}$, while a local heater allows a controlled increase of the temperature. The electron energy for the SEY measurements is scanned in the range $150-1200 \mathrm{eV}$. In order to limit the irradiation of the sample, the electron beam is pulsed with $80 \mathrm{~ms}$ pulse length at a current of about $1 \times 10^{-7}$ A. The secondary electrons are detected on a positively biased collector $(+45 \mathrm{~V})$ coaxial with the beam, while the sample is negatively biased $(-9 \mathrm{~V})$. The sample current $I_{s}$ and collector current $I_{c}$ are measured simultaneously, and the SEY is calculated according to $\delta=I_{c} /\left(I_{c}+I_{s}\right)$. The results have a standard deviation of \pm 0.07 for three subsequent experiments. The dose for each SEY measurement including 21 data points at different electron energies is about $10^{-7} \mathrm{C} \mathrm{mm}^{-2}$ (equivalent to about $5 \times 10^{11}$ electrons per $\mathrm{mm}^{2}$ ). As discussed in Ref. [14], this dose is well below the level of damage of the adsorbates and cannot produce any substantial surface modification. Stability of the SEY under electron bombardment ("conditioning") is investigated by continuous irradiation at an electron energy of $250 \mathrm{eV}$, the beam current being approximately doubled and the beam size increased from 7 to $11 \mathrm{~mm}^{2}$, in order to cover an area larger than the measurement spot.

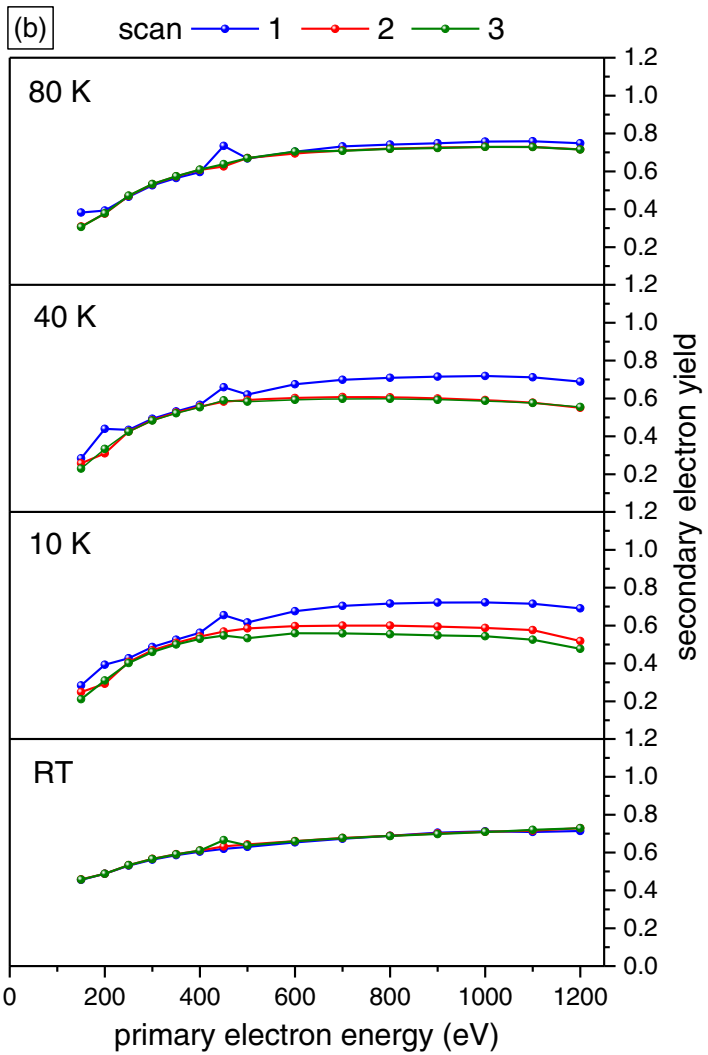

FIG. 2. (a) Variation of the energy dependence of the SEY for a CH-patterned air-treated sample, for three consecutive measurements at each temperature (RT denotes the measurements at room temperature). (b) Variation of the energy dependence of the SEY for a CHpatterned air-treated sample after thermal treatment and short air exposure, for three consecutive measurements at each temperature. The peak at $450 \mathrm{eV}$ is an artifact of the measurement. 


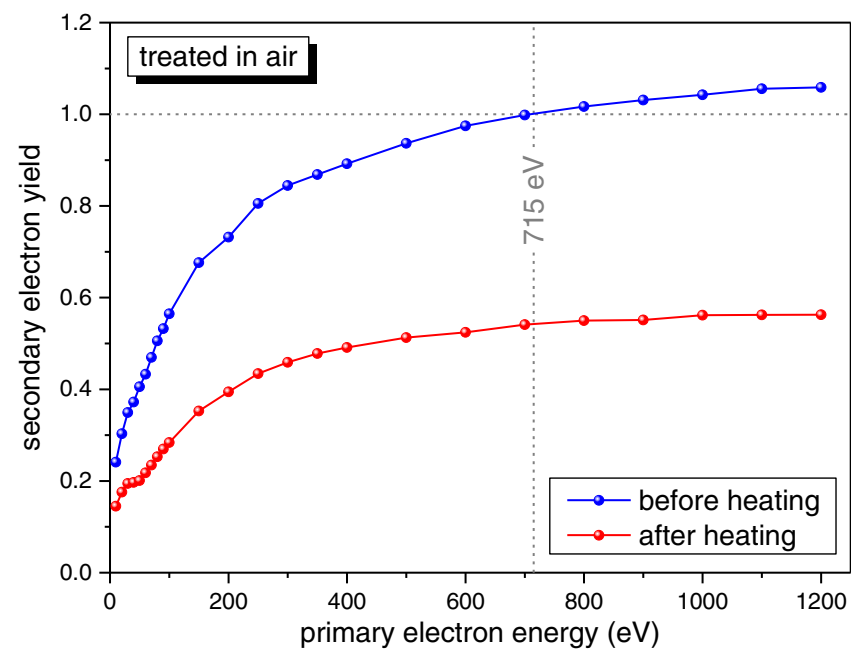

FIG. 3. Room-temperature SEY curves measured on the $\mathrm{CH}$ patterned air-treated sample before (blue line) and after (red line) thermal treatment at $300^{\circ} \mathrm{C}$ in a vacuum (no air exposure after heat treatment). The energy for which the SEY increases above unity is indicated.

\section{EXPERIMENTAL RESULTS}

Two identical samples treated in air with the $\mathrm{CH}$ pattern were measured in the cold-SEY system. After bakeout $\left(120^{\circ} \mathrm{C}\right.$ for each sample), the SEY was measured first at room temperature. Afterward, the samples were cooled down to approximately $10 \mathrm{~K}$, and, subsequently, the temperature was increased stepwise to 40,80 , and $95 \mathrm{~K}$, measuring the secondary electron yield at each temperature as indicated in Fig. 2(a). The measurements were repeated several times, displaying progressively a reduction in the SEY at a low temperature. Upon increasing the temperature, the samples did not seem, however, to retain any memory of the improvement in the SEY measured at the lower temperature step. In fact, by comparing the first measurement on each curve, it appears that the variations with the temperature are very weak and not monotonic, all within the measurement uncertainty. This effect was observed on both samples.

One of the samples was cooled to $10 \mathrm{~K}$ a second time and irradiated with an electron dose up to about $1.8 \times$ $10^{-6} \mathrm{C} \mathrm{mm}^{-2}$ (a $20 \times$ higher dose compared to a single measurement) in two steps of 5 and 10 min duration. The SEY measured at the end of each irradiation step was higher than at the beginning; however, subsequent measurements showed a decreasing trend similar to what is visible in Fig. 2.

The other sample was instead transferred to the XPS spectrometer to be heated in a vacuum at $300^{\circ} \mathrm{C}$ for $4 \mathrm{~h}$. The corresponding room-temperature SEY curves and XPS spectra before and after thermal treatment are shown in Figs. 3 and 4, respectively. The heat treatment results in a strong reduction of the SEY. The sample was then exposed to air to be transferred again to the cold-SEY system, and SEY results acquired, following the same procedure as discussed above, are displayed in Fig. 2(b). The cold-SEY measurements confirm the reduction of the SEY after heat treatment; however, the measurements at a low temperature still exhibit a change in the SEY during measurement as for the previous experiment (Fig. 2).

The XPS spectra of the sample before heating (Fig. 4, black line) indicate the existence of a $\mathrm{CuO}$ layer, as they agree with reference spectra $[15,16]$ and the $\mathrm{Cu}^{2+}$ in $\mathrm{CuO}$ exhibits an observable collection of satellite features in the $\mathrm{Cu} 2 \mathrm{p}$ spectrum at $943 \mathrm{eV}$. The $\mathrm{Cu} 2 \mathrm{p}_{3 / 2}$ state is found at $933.9 \mathrm{eV}$ binding energy (BE), and the $\mathrm{Cu} \mathrm{L}_{3} \mathrm{M}_{4,5} \mathrm{M}_{4,5}$ Auger transition is located at $917.3 \mathrm{eV}$ kinetic energy (KE),

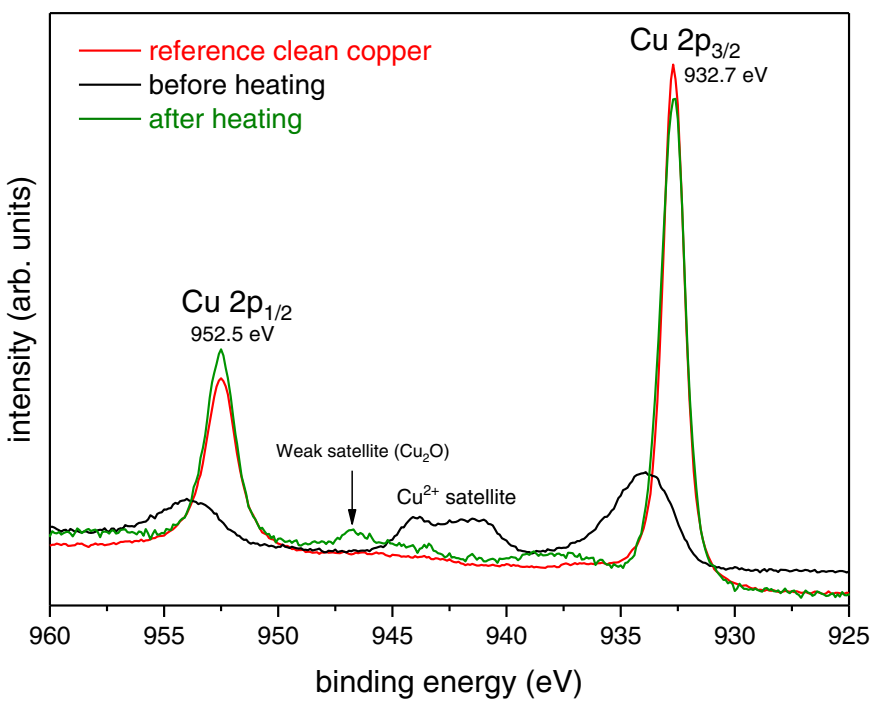

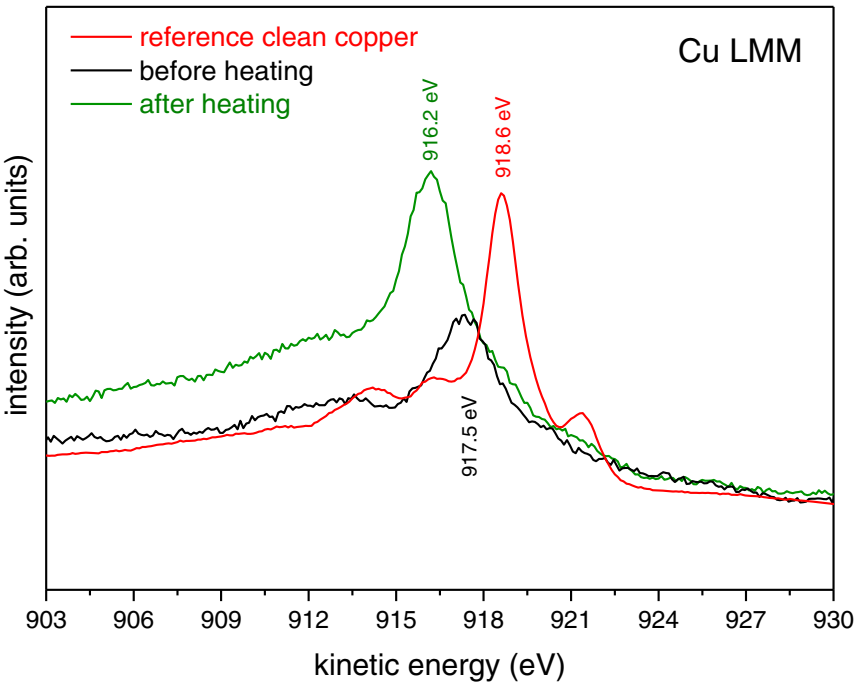

FIG. 4. X-ray photoelectron spectra of the $\mathrm{Cu} 2 \mathrm{p}$ state (left) and the Cu LMM Auger transition (right) of sputter-cleaned copper (red line) and $\mathrm{CH}$-patterned air-treated copper before (black line) and after (green line) the thermal treatment in a vacuum. 
TABLE I. Surface composition (in at. \%) based on a quantitative XPS analysis for $\mathrm{Cu}$ surfaces after laser treatment in different atmospheres. The numbers are given for samples measured as prepared after transport and insertion into the analysis system, while the values in brackets are determined after UHV annealing of the samples that had been laser treated in air or $\mathrm{N}_{2}$, respectively.

\begin{tabular}{lcccc}
\hline \hline & $\mathrm{Cu}$ & $\mathrm{O}$ & $\mathrm{C}$ & $\mathrm{N}$ \\
\hline Air & 21.5 & 52.9 & 5.3 & $\ldots$ \\
& $(63.2)$ & $(22.5)$ & $(1.8)$ & $\ldots$ \\
$\mathrm{N}_{2}$ & 34.3 & 37.1 & 13.7 & 6.2 \\
& $(69.2)$ & $(7.2)$ & $(9.3)$ & $(14.2)$ \\
$\mathrm{Ar}$ & 19.3 & 50.2 & 17.3 & $\cdots$ \\
\hline \hline
\end{tabular}

leading to an Auger parameter of $1851.2 \mathrm{eV}$ [17]. After heat treatment at $300^{\circ} \mathrm{C}$ (Fig. 4, green line), this feature no longer exists, and the main $\mathrm{Cu} 2 \mathrm{p}_{3 / 2}$ peak is shifted to a lower BE of $932.7 \mathrm{eV}$. The shape of the $\mathrm{Cu} 2 \mathrm{p}$ spectrum including the weak satellite structure at $947 \mathrm{eV}$ and the $\mathrm{Cu}$ LMM spectrum with an Auger parameter of $1848.9 \mathrm{eV}$ after heating agree with reported measurements on $\mathrm{Cu}_{2} \mathrm{O}$ $[17,18,19]$ and do not fit to clean $\mathrm{Cu}$ after $\mathrm{Ar}^{+}$sputtering (Fig. 4, red line). Consequently, the treatment in a vacuum at $300^{\circ} \mathrm{C}$ thermally reduces the initial $\mathrm{CuO}$ layer to $\mathrm{Cu}_{2} \mathrm{O}$.

Assuming a homogenous elemental distribution, we have estimated the surface composition using cross sections calculated from Ref. [20] and accounting for the energy dependence of the inelastic mean free path and the analyzer transmission function [21]. The first row of data in Table I shows the estimated values for the sample treated in air before and after vacuum annealing. The chemical reduction of the $\mathrm{CuO}$ surface to $\mathrm{Cu}_{2} \mathrm{O}$ during annealing is also represented by a strong decrease of the oxygen content, while the initially already relatively low number of carbon surface impurities is further diminished via thermally activated desorption of surface adsorbates.

The scanning electron microscope (SEM) images in Fig. 5, acquired using two different samples, show the typical cauliflowerlike nanostructures that are formed at the surface of the trench pattern (generated by the scanned laser) of the microstructured $\mathrm{Cu}$ support [13]. From the
SEM images, there is no visible change in the size and distribution of the redeposited copper nanoparticles between the pristine and the heat-treated samples.

To further assess the effect of the surface oxide and investigate its role in the SEY of laser-treated $\mathrm{Cu}$ surfaces, several samples have been structured in different process gases, namely, nitrogen, argon, and air as a reference. Room-temperature SEY measurements of these LHpatterned samples are illustrated in Fig. 6. The SEY curve of the sample treated in air has a maximum SEY value $\delta_{\max } \approx 0.84$ at the highest measured primary electron energy of $1200 \mathrm{eV}$, in agreement with previous results [13]. The SEY of the sample treated in nitrogen is considerably lower, having $\delta_{\max } \approx 0.66$ in the primary energy range 800-1000 eV. The SEY curve of the sample treated in argon is instead higher, with SEY $<1$ only for energies below $250 \mathrm{eV}$ and $\delta_{\max } \approx 1.1$ at $500 \mathrm{eV}$, and its shape differs significantly from the others.

The corresponding results of XPS measurements are illustrated in Fig. 7 and are compared to spectra of a sputtercleaned copper sample. The analysis indicates the presence of copper oxide $(\mathrm{CuO})$ on the sample treated in air, visible from the $\mathrm{Cu}^{2+}$ satellite around $943 \mathrm{eV}$ and the $\mathrm{Cu} 2 \mathrm{p}_{3 / 2}$ binding energy as well as from the $\mathrm{Cu}$ LMM transition at 917.6 eV KE [15] resulting in an Auger parameter of $1851.2 \mathrm{eV}$ (spectra not shown), similarly to the previous $\mathrm{CH}$-patterned sample. The surface of the sample treated in nitrogen is less oxidized [18], as the $\mathrm{Cu} 2 \mathrm{p}_{3 / 2}$ state at $932.8 \mathrm{eV}$ is close to the $\mathrm{BE}$ of clean copper and $\mathrm{Cu}_{2} \mathrm{O}$ $[16,17]$ and only a slight satellite feature at $943 \mathrm{eV}$ is detected. The LMM transition in this case is detected at 916.6 eV KE (Auger parameter $1849.4 \mathrm{eV}$ ), which indicates the formation of $\mathrm{Cu}_{2} \mathrm{O}$. In addition, a $\mathrm{N} 1 \mathrm{~s}$ signal at $397.5 \mathrm{eV}$ is detected, which corresponds to an estimated surface content of 6.2 at. \% (see Table I). In order to characterize the incorporation of nitrogen, we performed UHV annealing at $300^{\circ} \mathrm{C}$ of the sample treated in $\mathrm{N}_{2}$. While the initial oxide contributions in the $\mathrm{Cu} 2 \mathrm{p}$ and $\mathrm{O} 1 \mathrm{~s}$ spectra were strongly reduced in intensity, the $\mathrm{N} 1 \mathrm{~s}$ signal remained unchanged, and the surface content thus increased to 14.2 at. \%. The $\mathrm{N} \mathrm{1s}$ binding energy and the $\mathrm{Cu} 2 \mathrm{p}$ spectral distribution $[22,23]$ as well as the thermal stability [24] of
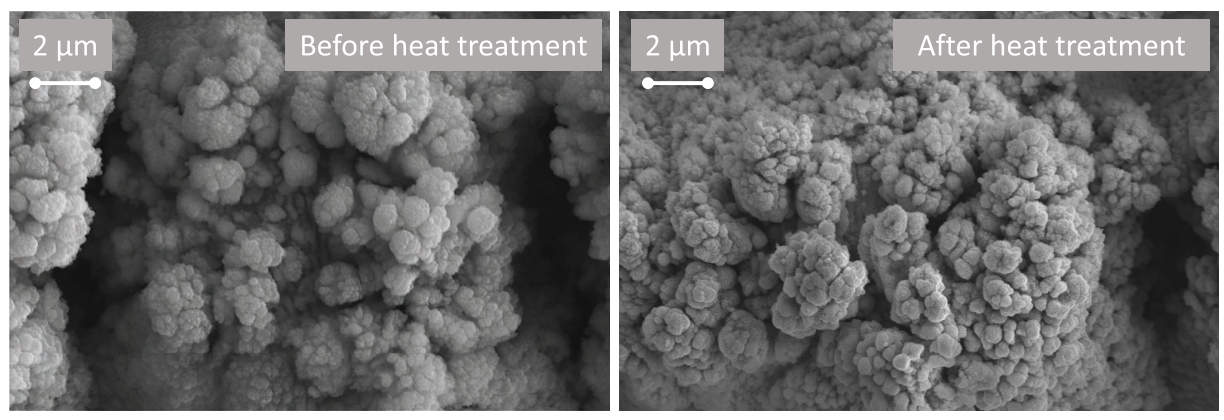

FIG. 5. SEM images of the sample after heat treatment compared to a similar reference sample before heat treatment. 


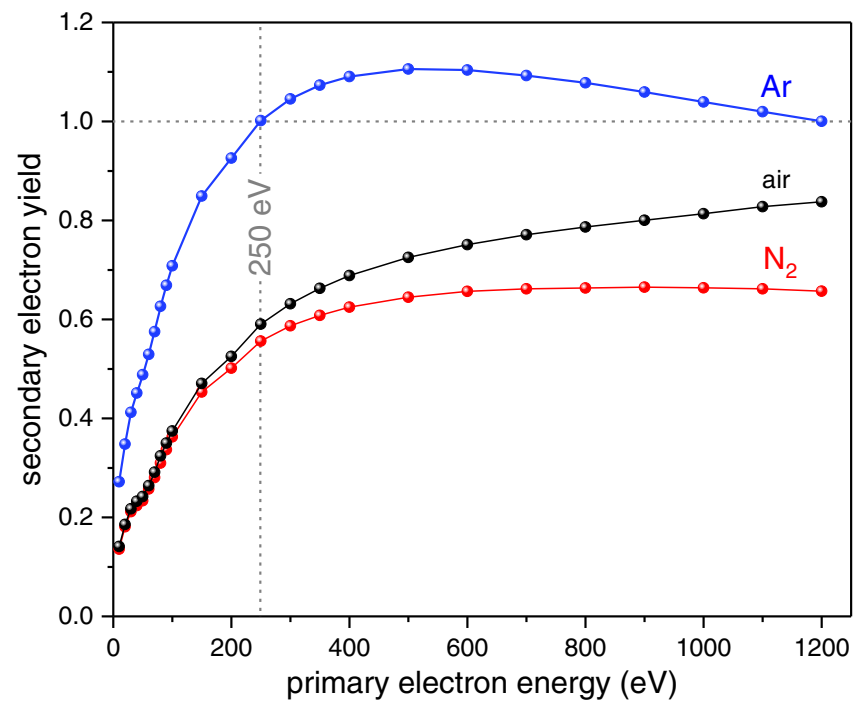

FIG. 6. Room-temperature SEY results of LH-patterned $\mathrm{Cu}$ samples treated in nitrogen (red line), argon (blue line), and air (gray line). The results are the average of three measurements at different locations at the sample. The energy for which the SEY increases above unity is indicated.

the nitrogen content indicate the partial formation of a $\mathrm{Cu}_{3} \mathrm{~N}$ surface passivation during the laser treatment in $\mathrm{N}_{2}$. In the case of $\mathrm{Cu}_{3} \mathrm{~N}$, the copper atoms are in oxidation state $\mathrm{Cu}^{1+}$, as they are in $\mathrm{Cu}_{2} \mathrm{O}$. In accordance, the $\mathrm{Cu} 2 \mathrm{p}$ spectra of $\mathrm{Cu}_{2} \mathrm{O}$ of $\mathrm{Cu}_{3} \mathrm{~N}$ are quite similar in spectral shape and core level binding energy $[16,20]$ as well as Auger parameter [17,21].

The spectra of the sample treated in argon and the determined surface composition suggests oxidation of the surface (the presence of $\mathrm{Cu}_{2} \mathrm{O}$ and hydroxide surface groups), which can be identified by the binding energy of the two features in the $\mathrm{Cu} 2 \mathrm{p}_{3 / 2}$ state at 934.3 and $932.3 \mathrm{eV} \mathrm{BE}$, the rather broadened appearance of the $\mathrm{Cu}$ LMM Auger line with a maximum at $917.0 \mathrm{eV} \mathrm{KE}$, and the shape of the $\mathrm{Cu} 2 \mathrm{p}$ satellite features [25]. The surface stoichiometry could be either induced by reactions with impurities in the inert gas during processing or by posttreatment reactions in air, if the laser processing in argon creates a nonpassivated and, hence, reactive surface.

The SEY of the samples treated in nitrogen, argon, and air atmosphere measured with the cold-SEY system are reported in chronological measurement order in Figs. 8-10, respectively. In all cases, a reference measurement at room temperature was performed first after bakeout of the system, followed by the measurements at a low temperature $(\approx 10 \mathrm{~K})$. The SEY values measured at room temperature in the two experimental systems are consistent within \pm 0.1 , compatible with the instrumental uncertainties.

The SEY measured at a low temperature is higher than the value measured at room temperature for the sample treated in nitrogen (Fig. 8), while the values are almost the same for the sample treated in argon (Fig. 9). The SEY measurement was repeated several times without observing any variation of the results for these two samples. After irradiation of the samples with doses of $6.1 \times$ $10^{-6} \mathrm{C} \mathrm{mm}^{-2}$ and up to $1.8 \times 10^{-5} \mathrm{C} \mathrm{mm}^{-2}$ (corresponding to 5 and $10 \mathrm{~min}$ of constant irradiation, respectively, similar to what done on the $\mathrm{CH}$-patterned samples), a progressive reduction of the SEY values is observed which remains stable upon further measurements. This conditioning process might be ascribed to desorption of surface adsorbates [14].

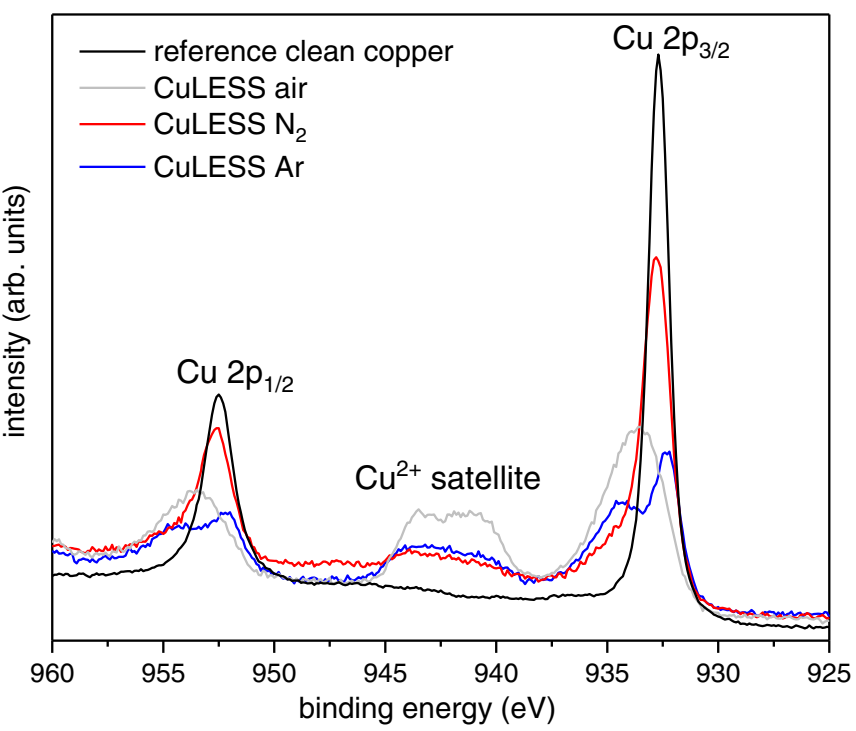

FIG. 7. XPS survey (left) and $\mathrm{Cu} 2 \mathrm{p}$ (right) spectra for samples treated under different atmospheres: nitrogen (red line), argon (blue line), air (gray line), and reference sputtered copper (black line). 


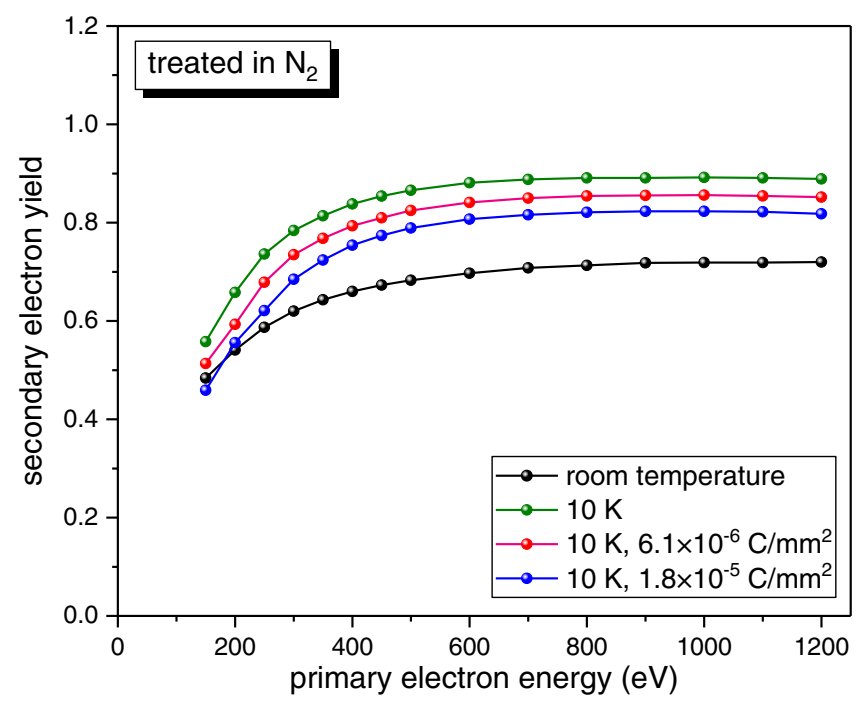

FIG. 8. SEY measurements of a LH-patterned sample treated in nitrogen atmosphere: at room temperature (black line), at $\approx 10 \mathrm{~K}$ (green line), and after exposure to an electron dose of $6.1 \times 10^{-6}$ (red line) and $1.8 \times 10^{-5} \mathrm{C} \mathrm{mm}^{-2}$ (blue line).

The behavior of the sample treated in air is entirely different but similar to that already reported for $\mathrm{CH}$ patterned samples. The measurement at a low temperature does not differ much from the measurement at room temperature, but when repeating the SEY measurement several times the curves decrease progressively. On the other hand, when irradiating this sample with the same doses as for the samples treated in an inert gas (Fig. 10), the measured SEY curves behave in a rather erratic way.

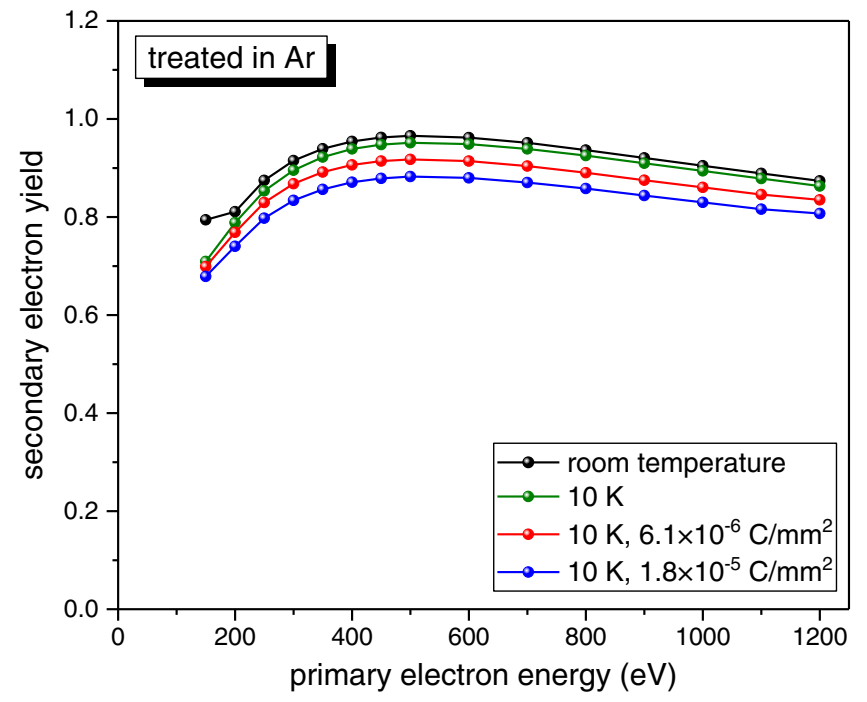

FIG. 9. SEY measurements of a LH-patterned sample treated in argon atmosphere: at room temperature (black line), at $\approx 10 \mathrm{~K}$ (green line), and after exposure to an electron dose of $6.1 \times 10^{-6}$ (red line) and $1.8 \times 10^{-5} \mathrm{C} \mathrm{mm}^{-2}$ (blue line).

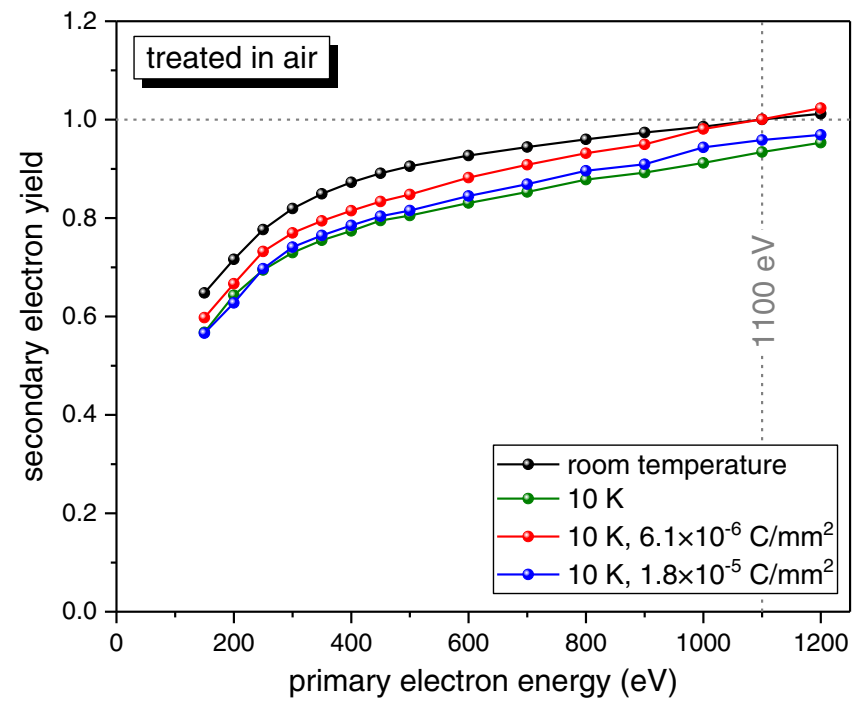

FIG. 10. SEY measurements of a LH-patterned sample treated in air: at room temperature (black line), at $\approx 10 \mathrm{~K}$ (green line), and after exposure to an electron dose of $6.1 \times 10^{-6}$ (red line) and $1.8 \times 10^{-5} \mathrm{C} \mathrm{mm}^{-2}$ (blue line). The energy for which the SEY increases above unity is indicated.

After completion of the SEY and XPS analyses, SEM images of the three differently treated samples were acquired as shown in Fig. 11. Even though the general enhancement of the surface to volume ratio is evident for all treatments, there are distinct differences in the microstructure of the redeposited nanoparticles.
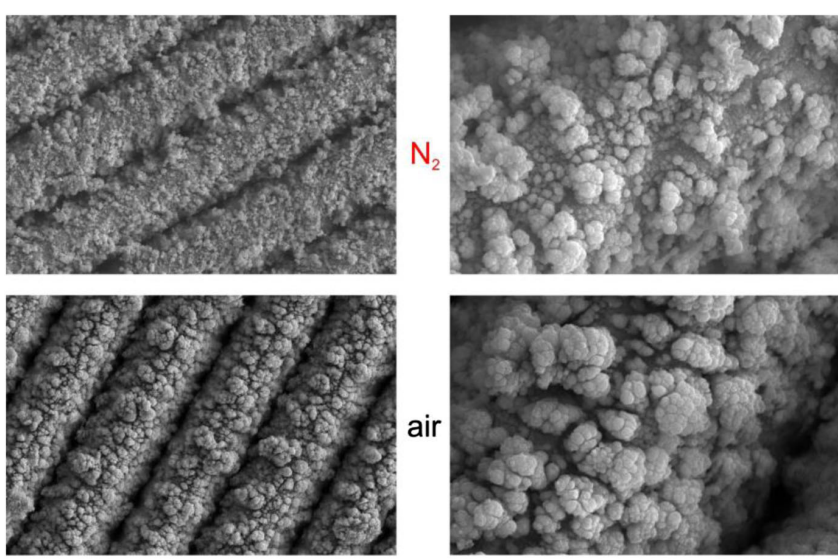

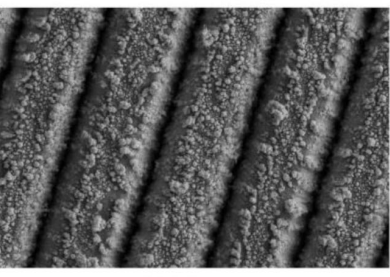

$50 \mu \mathrm{m}$

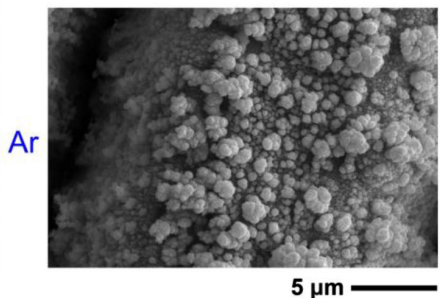

$5 \mu \mathrm{m}$
FIG. 11. Scanning electron micrographs of LH-patterned surfaces treated in nitrogen (top), air (middle), and argon (bottom) at two different magnifications. 


\section{DISCUSSION}

The measured strong decrease upon heat treatment of the SEY of the CH-patterned air-treated sample, illustrated in Fig. 3, can be directly correlated with the reduction of $\mathrm{CuO}$ to $\mathrm{Cu}_{2} \mathrm{O}$ shown in the XPS measurements in Fig. 4. The surface morphology of the reference sample and of the heat-treated one appear in fact to be substantially identical, as illustrated in Fig. 5, where the small differences in contrast could be attributed to the difference in oxidation state. An indirect confirmation that the surface geometry is unchanged is given by the fact that the two curves in Fig. 3 are proportional to each other with a proportionality factor of 1.85 and, thus, retain their overall shape, which typically depends mostly on surface topography [26].

In a similar way, the LH-patterned sample treated in air displays a higher SEY than the sample treated in nitrogen, as illustrated in Fig. 6. In this case, the main difference in the XPS analysis shown in Fig. 7 is the strong presence of $\mathrm{CuO}$ on the air-treated sample, compared to the almost entirely metallic $\mathrm{Cu}$ state with some $\mathrm{Cu}_{2} \mathrm{O}$ of the nitrogentreated one. Both samples display a similar morphology, illustrated in Fig. 11. The sample treated in air exhibits the highest packing density of particles at the surface covering the whole trench pattern of the microstructured $\mathrm{Cu}$ support. The particle coverage for the surfaces generated in nitrogen is almost comparable, but the variation of size is slightly larger, and the surface shape is more irregular, which might suggest a less efficient SEY reduction potential. These differences are insufficient (and with an opposing trend) to explain the large difference in SEY, which could thus be attributed mostly to the difference in surface oxidation. In all cases, the presence of $\mathrm{CuO}$ appears thus to be detrimental to the SEY. Experiments to produce and measure a reference $\mathrm{CuO}$ sample are in progress.

The presence of $\mathrm{CuO}$, although mostly reduced to $\mathrm{Cu}_{2} \mathrm{O}$ after heat treatment, leads probably to surface charging during electron bombardment at a low temperature and, thus, to the change of SEY shown in Fig. 2. CuO and $\mathrm{Cu}_{2} \mathrm{O}$ are both p-type semiconductors [27,28], and the occupation of the valence by thermally excited holes, the hole mobility, and the extrinsic defects in $\mathrm{Cu}_{x} \mathrm{O}$ determine their electrical conductivity. Although the hole mobility typically increases at a low temperature [29], this effect is more than compensated by the reduction of the concentration of charge carriers leading to a drastic reduction of the conductivity by several orders of magnitude $[30,31,32]$ for thin films. In the case of laser structuring, the surface is composed of separated oxidized copper nanoparticles which can, thus, be subject to charging at cryogenic temperatures if they are exposed to a flux of electrons as in the SEY measurements. This could explain the behavior of the air-treated samples at a low temperature, the surface charging leading to the erratic changes of SEY shown in Figs. 2 and 10, without any substantial conditioning effect.
For the sample treated in Ar, the attached particles on the surface are in tendency much smaller, and they do not form a densely closed cover layer (Fig. 11). Consequently, parts of the underlying $\mathrm{Cu}$ structure are visible in the SEM pictures. This difference in structure explains the different shape of the SEY curve for the treatment in Ar (Fig. 6). A maximum of the SEY $\delta_{\max } \approx 2$ around $300 \mathrm{eV}$ is typically found for flat copper [33], and the only partial coverage of the surface treated in Ar induces an intermediate SEY reduction $\left(\delta_{\max } \approx 1.3\right)$ with a moderate shift of the peak to a higher energy at around $500 \mathrm{eV}$. For the samples treated in air or $\mathrm{N}_{2}$, the more complete nanoparticle coverage allows for a much more efficient SEY reduction, with the peak potentially being shifted to energies above our maximum experimental value [34].

The variations in morphology between the three gases are in agreement with the current literature. The presence of oxygen favors the coalescence and appearance of redeposited nanoparticles during laser ablation $[35,36]$ and the formation of $\mathrm{CuO}$ at their surface. Nitrogen appears also to favor the coalescence of nanoparticles, probably through surface reaction with copper, resulting in a nonoxidized nanostructured surface which stands postoxidation upon ambient air exposure [36,37]. Conversely, treatment in argon typically does not result in strong nanoparticle formation, and the surface is oxidized to $\mathrm{Cu}_{2} \mathrm{O}$ and copper hydroxide upon air exposure after treatment [35]. We have indeed observed a strong production of visible vapors during laser structuring in air and nitrogen, possibly correlated with the larger quantity of nanoparticles formed on the surface of the samples.

In summary, the comparison of structural SEM analysis with the SEY and XPS results reveals that the surface layers formed in different atmospheres have varying surface properties. The sample treated in air exhibits a thick and dense coverage of $\mathrm{CuO}$ particles, and the potential for SEY reduction is limited. In addition, this results in surface charging at cryogenic temperatures. The laser structuring in argon does not generate such a strong surface oxidation, leaving mostly $\mathrm{Cu}_{2} \mathrm{O}$ and $\mathrm{Cu}$ hydroxides, but at the same time the particle density at the surface is lower, leading to lower SEY reduction capability. The optimum treatment in terms of the SEY at room and low temperatures appears to be the laser processing in $\mathrm{N}_{2}$, since it combines the advantages of generating a relatively high nanoparticle density for efficient SEY reduction with the circumstance that these remain mainly metallic, preventing any surface charging or any other phenomena detrimental to the SEY.

\section{CONCLUSIONS AND OUTLOOK}

Laser surface structuring for SEY reduction has been performed on copper samples, in different gas atmospheres. Samples that underwent structuring in air exhibit an oxidized surface, mostly in the form of $\mathrm{CuO}$, which charges when exposed to an electron beam at cryogenic 
temperatures, impairing a correct SEY measurement. On the other hand, laser treatment in $\mathrm{N}_{2}$ or Ar strongly decreases oxide formation, with the sample treated in $\mathrm{N}_{2}$ displaying an almost entirely metallic $\mathrm{Cu}$ state, allowing stable and reproducible performance of secondary electron emission characteristics. The $e$-cloud suppression properties of laser-structured surfaces of beam pipes at cryogenic temperatures in particle accelerators such as the HL-LHC might also be affected by charging effects at the surface oxide. Therefore, a laser treatment in a protective atmosphere can promote safe and reproducible accelerator performance. To this extent, LESS produced in $\mathrm{N}_{2}$ has demonstrated the lowest SEY at room and cryogenic temperatures in our experiments and is, therefore, the most promising procedure for a future large-scale implementation [11].

\section{ACKNOWLEDGMENTS}

The laser structuring at the University of Dundee was conducted under the aegis of grants and financial support from the Science and Technology Facilities Council (Grant No. ST/P00086X/1) and CERN (Collaboration Agreement KN3362).

[1] F. Zimmermann, Review of single bunch instabilities driven by an electron cloud, Phys. Rev. Accel. Beams 7, 124801 (2004).

[2] M. Tobiyama, J. W. Flanagan, H. Fukuma, S. Kurokawa, K. Ohmi, and S. S. Win, Coupled bunch instability caused by an electron cloud, Phys. Rev. Accel. Beams 9, 012801 (2006).

[3] F. Zimmermann, Electron-cloud effects in past and future machines-Walk through 50 years of electron-cloud studies, https://doi.org/10.5170/CERN-2013-002.9.

[4] P. Chiggiato and P. C. Pinto, Ti-Zr-V non-evaporable getter films: From development to large scale production for the Large Hadron Collider, Thin Solid Films 515, 382 (2006).

[5] G. Skripka and G. Iadarola, Beam-induced heat loads on the beam screens of the inner triplets for the HL-LHC, Report No. CERN-ACC-NOTE-2018-0009, https:// doi.org/10.17181/CERN.I7WJ.TNS9.

[6] G. Iadarola, E. Metral, and G. Rumolo, Beam induced heat loads on the beam-screens of the twin-bore magnets in the IRs of the HL-LHC, CERN Internal Note No. CERNACC-2016-0112, https://doi.org/10.17181/CERN.ENUJ .1L15.

[7] P. C. Pinto, S. Calatroni, H. Neupert, D. Letant-Delrieux, P. Edwards, P. Chiggiato, M. Taborelli, W. Vollenberg, C. Yin-Vallgren, J. L. Colaux, and S. Lucas, Carbon coatings with low secondary electron yield, Vacuum 98, 29 (2013).

[8] P. Chiggiato, Beam screen coating, in Proceedings of the LHC Performance Workshop, Chamonix, 2018 (to be published), https://indico.cern.ch/event/676124/ contributions/2775544/.
[9] G. Tang, A. C. Hourd, and A. Abdolvand, Nanosecond pulsed laser blackening of copper, Appl. Phys. Lett. 101, 231902 (2012).

[10] R. Valizadeh, O. B. Malyshev, S. Wang, S. A. Zolotovskaya, W. A. Gillespie, and A. Abdolvand, Low secondary electron yield engineered surface for electron cloud mitigation, Appl. Phys. Lett. 105, 231605 (2014).

[11] M. Sitko, V. Baglin, S. Calatroni, P. Chiggiato, B. Di Girolamo, E. G.-T. Valdivieso, M. Taborelli, M. Colling, T. Jones, P. McIntosh, D. Bajek, S. Wackerow, and A. Abdolvand, Towards implementation of laser engineered surface structures for electron cloud mitigation, in Proceedings of the 9th International Particle Accelerator Conference (IPAC'18), Vancouver (JACoW, Geneva, 2018), pp. 1220-1223, https://doi.org/10.18429/JACoWIPAC2018-TUZGBE3.

[12] L. Ferreira and M. Malabaila, Cleaning procedure for copper parts, CERN EDMS Document No. 1084640, https://edms.cern.ch/document/1084640/1.

[13] S. Calatroni, E. G.-T. Valdivieso, H. Neupert, V. Nistor, A. T. P. Fontenla, M. Taborelli, P. Chiggiato, O. Malyshev, R. Valizadeh, S. Wackerow, S. A. Zolotovskaya, W. A. Gillespie, and A. Abdolvand, First accelerator test of vacuum components with laser-engineered surfaces for electron-cloud mitigation, Phys. Rev. Accel. Beams 20, 113201 (2017).

[14] A Kuzucan, H. Neupert, M. Taborelli, and H. Störi, Secondary electron yield on cryogenic surfaces as a function of physisorbed gases, J. Vac. Sci. Technol. A 30, 051401 (2012).

[15] J. Ghijsen, L. H. Tjeng, J. van Elp, H. Eskes, J. Westerink, G. A. Sawatzky, and M. T. Czyzyk, Electronic structure of $\mathrm{Cu}_{2} \mathrm{O}$ and $\mathrm{CuO}$, Phys. Rev. B 38, 11322 (1988).

[16] T. Schedel-Niedrig, T. Neisius, I. Böttger, E. Kitzelmann, G. Weinberg, D. Demuth, and R. Schlögl, Copper (sub) oxide formation: A surface sensitive characterization of model catalysts, Phys. Chem. Chem. Phys. 2, 2407 (2000).

[17] M. C. Biesinger, Advanced analysis of copper x-ray photoelectron spectra, Surf. Interface Anal. 49, 1325 (2017).

[18] S. Poulston, P. M. Parlett, P. Stone, and M. Bowker, Surface oxidation and reduction of $\mathrm{CuO}$ and $\mathrm{Cu}_{2} \mathrm{O}$ studied using XPS and XAES, Surf. Interface Anal. 24, 811 (1996).

[19] D. Tahir and S. Tougaard, Electronic and optical properties of $\mathrm{Cu}, \mathrm{CuO}$ and $\mathrm{Cu}_{2} \mathrm{O}$ studied by electron spectroscopy, J. Phys. Condens. Matter 24, 175002 (2012).

[20] J. J. Yeh and I. Lindau, Atomic subshell photoionization cross sections and asymmetry parameters: $1 \leq Z \leq 103$, At. Data Nucl. Data Tables 32, 1 (1985).

[21] M. P. Seah, The quantitative analysis of surfaces by XPS: A review, Surf. Interface Anal. 2, 222 (1980).

[22] C. Navío, M. J. Capitán, J. Álvarez, F. Yndurain, and R. Miranda, Intrinsic surface band bending in $\mathrm{Cu}_{3} \mathrm{~N}(100)$ ultrathin films, Phys. Rev. B 76, 085105 (2007).

[23] A. Fallberg, M. Ottosson, and J.-O. Carlsson, CVD of copper(I) nitride, Chem. Vap. Deposition 15, 300 (2009).

[24] Z. Q. Liu, W. J. Wang, T. M. Wang, S. Chao, and S. K. Zheng, Thermal stability of copper nitride films prepared by rf magnetron sputtering, Thin Solid Films 325, 55 (1998). 
[25] M. C. Biesinger, L. W. M. Lau, A. R. Gerson, and R.S.C. Smart, Resolving surface chemical states in XPS analysis of first row transition metals, oxides and hydroxides: Sc, Ti, V, Cu and Zn, Appl. Surf. Sci. 257, 887 (2010).

[26] M. Pivi, F. K. King, R. E. Kirby, T. O. Raubenheimer, G. Stupakov, and F. Le Pimpec, Sharp reduction of the secondary electron emission yield from grooved surfaces, J. Appl. Phys. 104, 104904 (2008).

[27] M. Heinemann, B. Eifert, and C. Heiliger, Band structure and phase stability of the copper oxides $\mathrm{Cu}_{2} \mathrm{O}, \mathrm{CuO}$, and $\mathrm{Cu}_{4} \mathrm{O}_{3}$, Phys. Rev. B 87, 115111 (2013).

[28] B. K. Meyer, A. Polity, D. Reppin, M. Becker, P. Hering, P. J. Klar, Th. Sander, C. Reindl, J. Benz, M. Eickhoff, C. Heiliger, M. Heinemann, J. Bläsing, A. Krost, S. Shokovets, C. Müller, and C. Ronning, Binary copper oxide semiconductors: From materials towards devices, Phys. Status Solidi B 249, 1487 (2012).

[29] H. Shimada and T. Masumi, Hall mobility of positive holes in $\mathrm{Cu}_{2} \mathrm{O}$, J. Phys. Soc. Jpn. 58, 1717 (1989).

[30] G. Beensh-Marchwicka, L. Kròl-Stępniewska, and M. Słaby, Effect of the oxygen pressure during sputtering on the properties of thin $\mathrm{CuO}_{x}$ films, Thin Solid Films 88, 33 (1982).

[31] A. K. Mukhopadhyay, A. K. Chakraborty, A. P. Chatterjee, and S. K. Lahiri, Galvanostatic deposition and electrical characterization of cuprous oxide thin films, Thin Solid Films 209, 92 (1992).

[32] X. G. Zheng, N. Tsutsumi, S. Tanaka, M. Suzuki, and C. N. $\mathrm{Xu}$, Electric and magnetic anomaly in single crystalline $\mathrm{CuO}$, Physica (Amsterdam) 321C, 67 (1999).

[33] R. Larciprete, D. R. Grosso, M. Commisso, R. Flammini, and R. Cimino, Secondary electron yield of $\mathrm{Cu}$ technical surfaces: Dependence on electron irradiation, Phys. Rev. Accel. Beams 16, 011002 (2013).

[34] K. Nishimura, T. Itotani, and K. Ohya, Influence of surface roughness on secondary electron emission and electron backscattering from metal surface, Jpn. J. Appl. Phys. 33, 4727 (1994).

[35] P. Stefanov, N. Minkovski, I. Balchev, I. Avramova, N. Sabotinov, and Ts. Marinova, XPS studies of short pulse laser interaction with copper, Appl. Surf. Sci. 253, 1046 (2006).

[36] T. Smausz, T. Csizmadia, C. Tápai, J. Kopniczky, A. Oszkó, M. Ehrhardt, P. Lorenz, K. Zimmer, A. Prager, and B. Hopp, Study on the effect of ambient gas on nanostructure formation on metal surfaces during femtosecond laser ablation for fabrication of low-reflective surfaces, Appl. Surf. Sci. 389, 1113 (2016).

[37] J. Li, J. W. Mayer, and E. G. Colgan, Oxidation and protection in copper and copper alloy thin films, J. Appl. Phys. 70, 2820 (1991). 